Raquel Fantin

DOMENICONI ${ }^{1}$

Antonio Marcos ORSI ${ }^{2}$

Maeli Dal Pai SILVA ${ }^{3}$

Célia Cristina Leme BEU ${ }^{1}$

Kátia da Silva Aparecida

VIEGAS ${ }^{4}$

Correspondência para:

ANTONIOMARCOSORSI

Docente Voluntário da UNESP

Departamento de Anatomia

UNESP, Botucatu, CP 510

18.618-000 Botucatu, SP

email:amorsi@ibb.unesp.br

Recebido para publicação: 23/03/2004 Aprovado para publicação: 01/06/2005

\title{
Localização histoquímica de algumas hidrolases no epidídimo do gerbilo
}

1 - Departamento de Biologia Celular e Estrutural da Universidade de Campinas

- Campinas - SP

2 - Departamento de Anatomia da do Instituto de Biociências da Universidade

Estadual Paulista - Botucatu - SP

3 - Departamento de Morfologiada do Instituto de Biociências da Universidade Estadual Paulista - Botucatu - SP

4 - Departamento de Anatomia dos Animais Domésticos e Silvestres da Faculdade de Medicina Veterinária e Zootecnia da Universidade de São Paulo - São Paulo - SP

\section{Resumo}

Neste estudo verificou-se, principalmente, que a expressão tissular da FoAl esteve presente nas regiões proximais do epidídimo de gerbilo. As reatividades da FoAc e da ATPase foram intensas (fortes), na maioria das regiões do epidídimo caracterizadas, marcadamente ao nível do citoplasma apical das células do epitélio tubular, exceto no corpo epididimal um delgado ístmo de conexão da cabeça à cauda epididimárias nesta espécie, com notória hiporeatividade enzimática a praticamente todas as enzimas aqui estudadas. A SDH mostrou também fraca atividade em todas as regiões, e estruturas do ducto epididimário do gerbilo, exceto no compartimento intraluminal onde se verificou atividade SDH-intensa nos espermatozóides estocados no lúmen. As reações enzimáticas caracterizadas foram correlacionadas com alguns papéis histofisiológicos tais como a mediação enzimática das fosfatases e ATPase em processos como endocitose, secreção, absorção e processo de transporte ativo das células do epitélio tubular. Uma possível marcação específica de mitocôndrias da peça média dos espermatozóides intraluminais pela SDH foi sugerida, com embasamento em processos metabólicos das mitocôndrias.

\section{Introdução}

A fosfatase ácida (FoAc) e a fosfatase alcalina (FoAl) mostraram localizações distintas no epitélio epididimário de alguns mamíferos. Assim sendo, a FoAl reagia positivamente na borda microvilosa (de estereocílios) de todo o epidídimo, enquanto que a FoAc reagia fortemente nos dois segmentos epididimários proximais, localizados na cabeça epididimal de alguns mamíferos, como o coelho, cavalo, touro e carneiro $^{1,2}$. Estes resultados foram similares às descrições feitas no epidídimo de outros mamíferos, destacando-se os roedores laboratoriais ${ }^{3,4}$.

A FoAc usualmente está associada com absorção e quebra de compostos sob condições ácidas, a nível lisosomal ${ }^{5}$, estando também envolvida no catabolismo de substâncias, previamente absorvidas do lúmen do ducto epididimal ${ }^{6,7}$. Atualmente, se conhece que a função hidrolítica da FoAc está ligada aos processos de digestão autofágica e heterofágica dos lisossomos, os quais estão presentes principalmente no citoplasma apical de células epiteliais dos dúctulos eferentes ${ }^{8}$ e do ducto epididimário ${ }^{6,9}$, justificando a sua atividade enzimática na parte apical do epitélio tubular destes ductos da via espermática ${ }^{8}$.

A sugestão proposta de que o segmento inicial é a principal região epididimária associada à reabsorção de 
fluido seminal ${ }^{6}$ fora antes sugerida ${ }^{3,6,10}$ pelas reações distintas para adenosina trifosfatase (ATPase) e fosfatase alcalina na margem microvilosa do segmento inicial. Ademais, um ciclo ativo de ácido tricarboxílico poderia ser esperado para possibilitar a formação de quantidades significativas de ATP, para ser utilizado no transporte ativo de metabólitos e íons para dentro ou para fora do lúmen tubular epididimário. A presença de tal atividade de transporte é indicada por uma intensa reação ATPase positiva e moderada atividade fosfatase alcalina ao longo da margem luminal do epitélio no segmento inicial ${ }^{11}$.

A atividade histo-enzimática da ATPase no epidídimo de mamíferos também está associada ao processo bioquímico de quebra do ATP, visando produção de energia para transporte ativo de substâncias entre a parte apical do epitélio e a luz epididimária, ou vice-versa ${ }^{4,11}$. A ATPase, através de estudo mais recente foi imunolocalizada na membrana plasmática ou na membrana de revestimento de vesículas apicais presentes em células do epitélio epididimário, sendo considerada transportadora de prótons $\mathrm{H}^{+}$para o lúmen tubular, visando acidificar o ambiente luminal e desta forma mantém a quiescência dos espermatozóides intraluminais ${ }^{12}$.

Reações enzimáticas intensas foram notadas para a succinato desidrogenase (SDH) e esterase não-específica, no segmento terminal epididimário do elefante, sendo indicativas de que a SDH estaria envolvida em considerável atividade metabólica, a qual poderia estar associada com a produção de substratos para os espermatozóides ${ }^{11}$. Por outro lado, no epidídimo de gato, de modo geral, a SDH deu reatividade fraca ao longo do epidídimo ${ }^{13}$. Por ser a SDH uma hidrolase com papel relevante no ciclo de Krebs poderia se especular que a sua reatividade fraca no epitélio epididimal decorreria do predomínio de glicólise anaeróbica no epidídimo ${ }^{14}$.

Estudo de localização histoquímica das enzimas: fosfatase alcalina (FoAl), fosfatase ácida (FoAc), ATPase e SDH, relacionadas ao metabolismo epididimário, foi aqui realizado com o objetivo de precisar a distribuição destas enzimas nas diferentes regiões do epidídimo do gerbilo ${ }^{15}$ e inferir os possíveis aspectos morfofuncionais dos diferentes segmentos epididimários.

\section{Materiais e Métodos}

Para estudos histoquímicos de atividades enzimáticas no epidídimo de gerbilo (Meriones unguiculatus), foram obtidos fragmentos adequados do segmento inicial (SI), cabeça, corpo e cauda de ambos os epidídimos de 7 gerbilos adultos e sexualmente maduros, com idade de 90 dias. As regiões foram coletadas a fresco e congeladas em n-hexana, previamente resfriada em nitrogênio líquido. Estes materiais foram acondicionados em freezer à $-80^{\circ} \mathrm{C}$. Cortes histológicos de $9 \mathrm{~mm}$ foram obtidos em micrótomo criostato (JungLeica CM 1800, Alemanha) à temperatura de $-20^{\circ} \mathrm{C}$ e submetidos às reações enzimáticas para pesquisas de localização e reatividade das enzimas: ATPase, fosfatases ácida e alcalina (FoAc e FoAl, respectivamente) e succinato desidrogenase $(\mathrm{SDH})^{16}$. Os parâmetros de coloração tissular (intensidade de reações), utilizados para documentar as respectivas reatividades enzimáticas foram convencionados como sendo de atividades: Ointensa (4), forte (3), moderada (2), fraca (1) e negativa (0).

\section{Resultados}

As localizações histoquímicas e as reatividades do ápice e da base do epitélio epididimário e da membrana basal (MB) do ducto epididimário do gerbilo são sumariadas na tabela 1 , sendo as reatividades analisadas nas regiões histológicas préestabelecidas ${ }^{15}$.

A enzima $\mathrm{FoAl}$ mostrou reatividades intensa no SI (Figura 1A) e forte na cabeça epididimária (Figura 2A). No SI a reação foi intensa na porção mais apical do epitélio 
epididimário e englobando o citoplasma supranuclear e apical das células principais (P) e talvez também das células apicais. A margem microvilosa apical mostrou reatividade entre fraca e negativa. A membrana basal exibiu reatividade forte; e o conteúdo luminal apresentou reatividade heterogênea, notando-se atividade enzimática forte em alguns pontos dispersos do conteúdo presente na luz tubular (Figura 1A).

No epitélio de revestimento da cabeça epididimária a atividade da FoAl foi forte também na porção apical, aparen-temente tendo a mesma localização histo-química observada no SI, porém a margem apical de microvilos na cabeça apresentou reatividade igualmente forte, diferentemente do SI, onde os microvilos tiveram reatividade negativa. $\mathrm{O}$ conteúdo luminal, com características mais homogêneas, mos-trou reatividade média e a membrana basal tubular exibiu uma reatividade forte (Figura 2A).

A atividade da FoAl no corpo epididimário foi de fraca a negativa no epitélio tubular, sendo negativa no conteúdo luminal e na membrana basal. $\mathrm{Na}$ cauda epididimária a reatividade da FoAl, de modo geral, foi negativa, exceto em nível da membrana basal tubular em que foi média (Figura 3A). Logo, se pôde observar que a atividade da FoAl diminuiu gradualmente do SI em direção ao corpo e cauda epididimários. Verificou-se que a atividade enzimática da FoAl estava concentrada na porção proximal do ducto epididimário do gerbilo, englobando o SI e a cabeça epididimária.

$\mathrm{Na}$ porção proximal do epidídimo do gerbilo a enzima FoAc mostrou atividades intensa no citoplasma supranuclear e apical e moderada no citoplasma basal das células do epitélio epididimário, tanto no SI (Figura 1B) como na cabeça epididimal (Figura 2B). Possivelmente a reatividade intensa ocorreu preponderantemente no citoplasma das células P. Porém não se pôde descartar as células apicais e claras impossíveis de se caracterizar histoquimicamente nos preparados enzimológicos. Os núcleos celulares não apresentaram reação enzimática e a evidenciação de atividade moderada basal-mente foi retratada por alguns pontos dispersos de reatividades forte ou intensa. A reatividade da membrana basal à FoAc foi negativa em ambas as regiões analisadas assim como o conteúdo luminal da cabeça epididimária, e o conteúdo luminal do SI mostraram pontos focais de reatividade moderada à FoAc.

A atividade da FoAc no corpo epididimário observou-se, novamente, ser de fraca a negativa. Na cauda epididimal a FoAc voltou a mostrar reatividade intensa na porção apical e entre forte e moderada na porção basal do epitélio tubular (Figura 3B). A membrana basal tubular deu reação negativa à FoAc, a qual mostrou atividades entre fraca e negativa no conteúdo intraluminal da cauda epididimal (Figura 3B). Observou-se que a atividade da FoAc foi intensa em praticamente toda a margem apical do epitélio epididimal do gerbilo, desde o SI até a cauda, exceto no corpo epididimário onde se observou reação entre fraca e negativa.

A enzima ATPase deu reatividades intensa na porção apical e fraca na porção basal do epitélio epididimal do SI, não mostrando atividade no terço médio basal do epitélio tubular, no qual os núcleos das células $\mathrm{P}$ foram observados, conforme as observações preliminares que se fez de histologia epididimária regional no gerbilo ${ }^{15}$. A membrana basal tubular assim como o conteúdo luminal mostraram reatividades fracas ou negativas (Figura 1C). Na cabeça epididimária a reatividade tubular geral à ATPase foi forte na parte apical do epitélio tubular, e, também na estreita faixa do citoplasma basal das células epiteliais. A membrana basal exibiu reação forte e o conteúdo luminal não apresentou reação à ATPase (Figura 2C).

O corpo epididimário do gerbilo teve atividade enzimática entre fraca e negativa em todas as regiões analisadas. $\mathrm{Na}$ cauda, a atividade da ATPase mostrou-se forte em nível apical e também no estroma peritubular do epitélio de revestimento tubular. A 
membrana basal tubular mostrou reatividade forte e no conteúdo luminal viu-se atividade entre fraca e negativa para à ATPase (Figura 3C). Notou-se que a região apical do epitélio epididimal mostrou reatividade de ATPase em todos os segmentos epididimários, exceto no corpo, onde a reatividade enzimática foi entre fraca e negativa. A intensidade da reação à ATPase diminuiu do SI para a cabeça e cauda epididimárias.

A enzima SDH, de modo geral, mostrou atividade predominantemente fraca no epitélio de revestimento do ducto epididimal do gerbilo em todas as regiões consideradas. No SI uma reação enzimática moderada foi vista basalmente (Fig.ura 1D) e no corpo epididimário não houve reatividade à SDH. Tanto na cabeça (Figura 2D) como na cauda (Figura 3D) epididimárias, notaram-se reações entre fraca e negativa para a $\mathrm{SDH}$. De modo mais específico no epitélio epididimal do SI foi observada reatividade moderada à SDH, sendo essa reação mais constante na região basal. Nas demais regiões histológicas esta reação diminuiu de intensidade tornando-se mais fraca e mais dispersa. Verificouse reatividade intensa de SDH apenas no conteúdo luminal, formado predominan-temente por espermatozóides (Figura 1D, 2D e 3D).

\section{Discussão}

A reatividade da FoAl no epidídimo do gerbilo permitiu observar que esta enzima está concentrada na porção proximal do ducto epididimário deste roedor, a qual engloba o SI e a cabeça epididimária ${ }^{15}$. Foi observada principalmente na porção apical do epitélio de revestimento tubular, englobando o citoplasma supranuclear e apical das células P e apicais ${ }^{15}$. Estas observações são, até certo ponto, similares àquelas caracterizadas no epidídimo de algumas outras espécies de mamíferos, embora no rato e no cobaio as células $\mathrm{P}$ não mostraram reatividades para esta enzima ${ }^{3,4}$. Por outro lado, à semelhança das observações anteriores, feitas no rato e em outros mamíferos ${ }^{4}$ e no cobaio $^{3}$, a membrana basal tubular epididimária do gerbilo mostrou reatividade predominantemente forte à $\mathrm{FoAl}$, cujo significado histofisiológico é a mediação enzimática que a $\mathrm{FoAl}$ exerce entre as células epiteliais e os capilares do estroma peritubular, no transporte de açúcares e outras moléculas orgânicas ${ }^{3}$.

Por outro lado, tendo em vista que a FoAl catalisa e hidrolisa ésteres de monofosfato, sendo predominantemente uma enzima da membrana plasmática com localização em superfícies adsortivas ou secretórias de células ${ }^{17}$, poder-se-ia inferir que os segmentos proximais do epidídimo do gerbilo estariam envolvidos ativamente com

Tabela 1 - Localizações histoquímicas e reatividades do ápice e da base do epitélio epididimário e da membrana basal (MB) do ducto epididimário do gerbilo, nas regiões histológicas préestabelecidas ${ }^{8}$. Botucatu, 2004

\begin{tabular}{|c|c|c|c|c|c|c|c|c|c|c|c|c|}
\hline \multirow{3}{*}{ 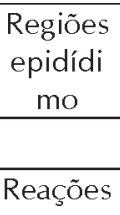 } & \multicolumn{3}{|c|}{ segmento inicial } & \multicolumn{3}{|c|}{ Cabeça } & \multicolumn{3}{|c|}{ Corpo } & \multicolumn{3}{|c|}{ Cauda } \\
\hline & \multicolumn{3}{|c|}{ Epitélio } & \multicolumn{2}{|c|}{ Epitélio } & \multirow[b]{2}{*}{$\mathrm{MB}$} & \multicolumn{2}{|c|}{ Epitélio } & \multicolumn{4}{|c|}{ Epitélio } \\
\hline & ápice & base & MB & ápice & Base & & Ápice & Base & $\mathrm{MB}$ & Ápice & Base & $M B$ \\
\hline FoAl & 4 & 0 & 3 & 3 & 0 & 3 & 1 & 1 & 0 & 0 & 0 & 2 \\
\hline FoAC & 4 & 2 & 0 & 4 & 2 & 0 & 1 & 0 & 0 & 4 & 3 & 0 \\
\hline ATPase & 4 & 1 & 1 & 3 & 3 & 3 & 1 & 1 & 1 & 3 & 1 & 1 \\
\hline $\mathrm{SDH}$ & 1 & 2 & 0 & 1 & 1 & 0 & 0 & 0 & 0 & 1 & 1 & 0 \\
\hline
\end{tabular}

(FoAl) fosfatase alcalina; (FoAc) fosfatase ácida; (ATPase) adenosina trifosfatase; (SDH) succinato desidrogenase

(4) reação intensa; (3) reação forte; (2) reação moderada; (1) reação fraca e (0) reação negativa 

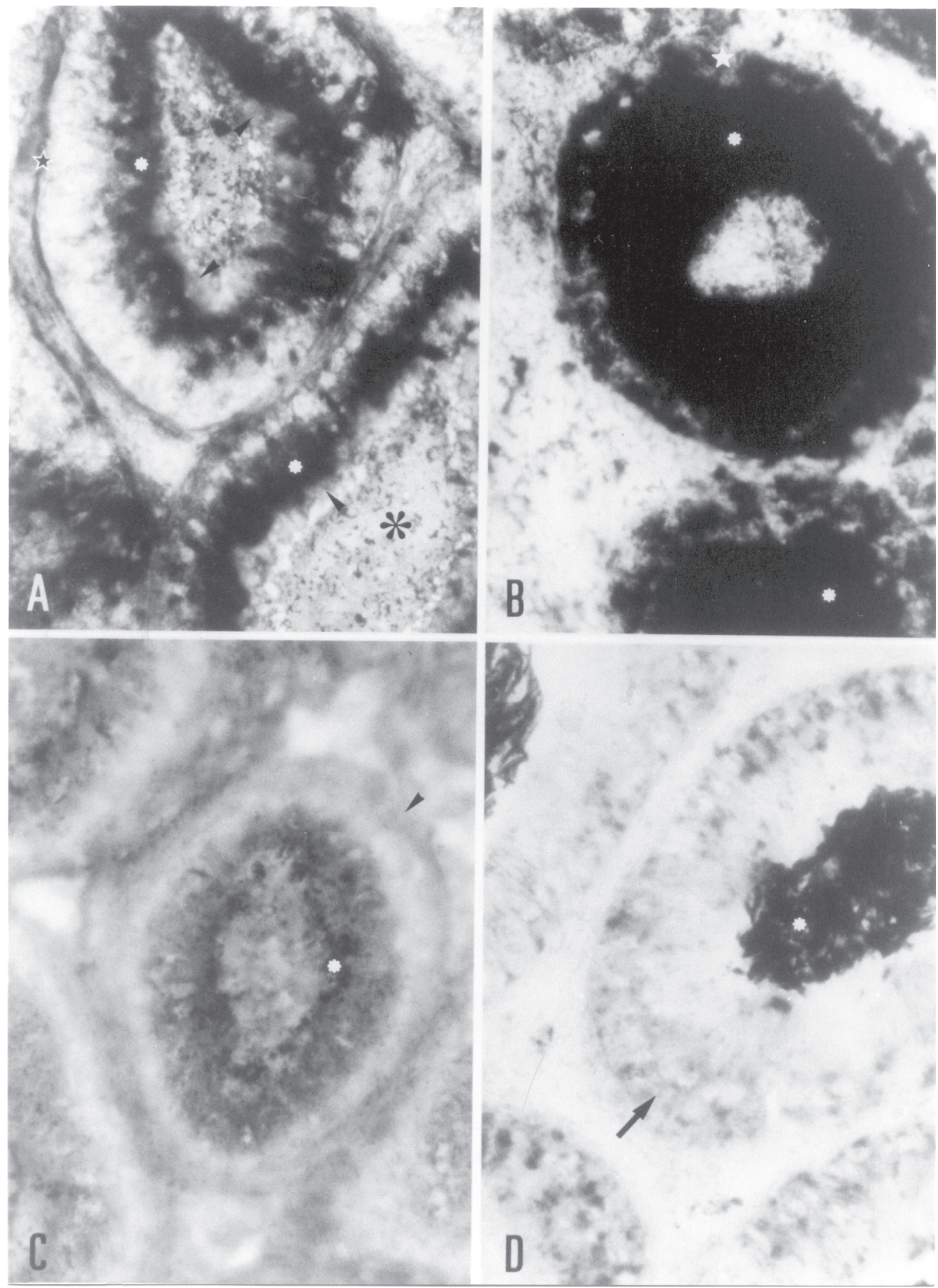

Figura 1 - Reatividades enzimáticas no SI do ducto epididimário do gerbilo às enzimas FoAl (A, 200x); FoAc (B, 200x); ATPase (C, 200x); e, SDH (D, 200x), sendo indicadas reações: intensa (rosáceas), forte (estrelas), heterogênea $\left({ }^{*}\right)$, fraca (cabeça de seta), moderada (seta) 

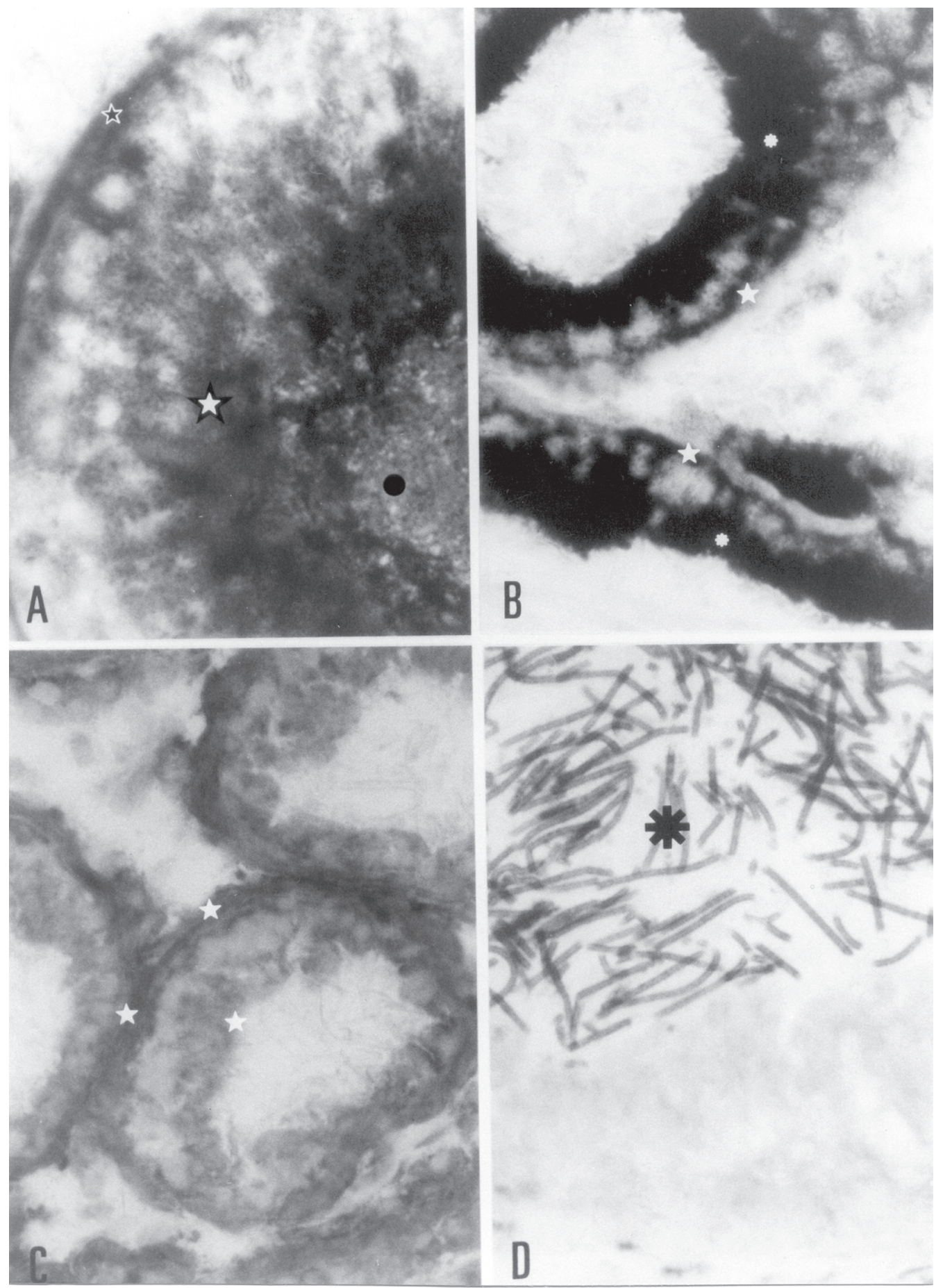

Figura 2 - Reatividades enzimáticas, na cabeça do ducto epididimário do gerbilo às enzimas FoAl (A, 400x); FoAc (B, 200x); ATPase (C, 200x); e, $\mathrm{SDH}(\mathrm{D}, 400 \mathrm{x})$, sendo indicadas reações: forte (estrelas), homogênea (esfera), intensa (rosáceas) 


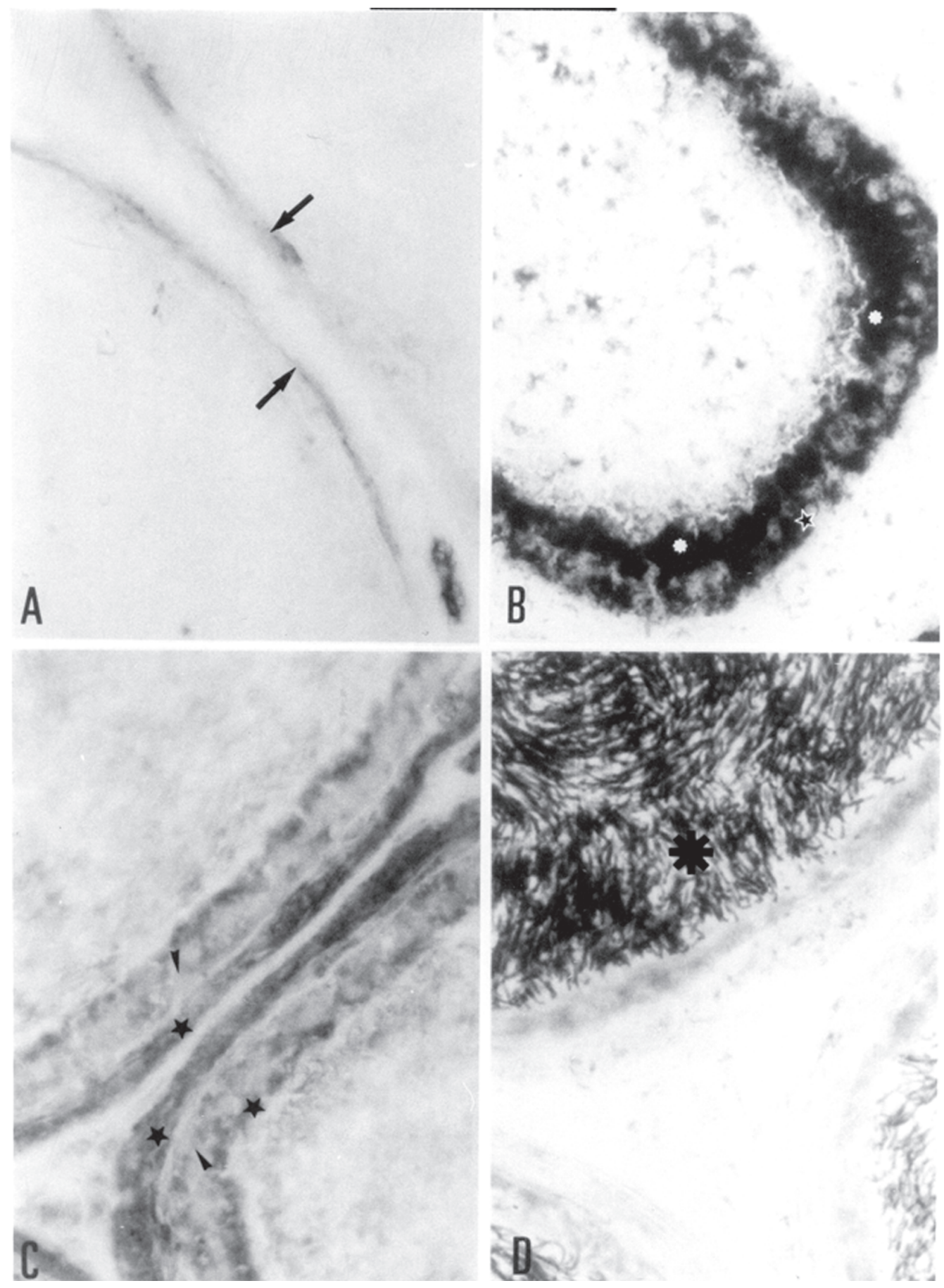

Figura 3 - Reatividades enzimáticas na cauda do ducto epididimário do gerbilo às enzimas FoAl (A, 200x); FoAc (B, 200x); ATPase (C, 200x); e, SDH (D, 200x), sendo indicadas reações: moderada (seta), intensa (rosáceas), forte (estrelas), fraca (cabeça de seta) 
estes papéis funcionais marcantes. Inclusive apoiaria esta tese a observação de atividades enzimáticas fortes de outras enzimas hidrolíticas neste segmento, exceto a SDH. As atividades endocitóticas, secretórias e de absorção, se relacionam a atividades metabólicas dos compartimentos epitelial e luminal do epidídimo ${ }^{6,9,18,19}$. Como conseqüência, apoiariam também uma possível habilitação de fertilização dos espermatozóides epididimários do gerbilo nos segmentos proximais do ducto, embora esta tenda a ocorrer mais em nível do segmento distal (cauda) no epidídimo de roedores ${ }^{19,20,21,22}$.

A atividade da FoAl na cauda epididimária do gerbilo foi negativa, exceto ao nível da membrana basal, resultado que apoia, talvez, a tese proposta de habilitação de fertilização dos espermatozóides ao nível dos segmentos proximais do epidídimo nesta espécie. Estes segmentos proximais precedem o delgado corpo epididimário ${ }^{8}$. Comparativamente ao hamster em que se verifica a habilitação de fertilização dos espermatozóides na cauda epididimária proximal $^{22,23,24}$, a reatividade da FoAl na cauda epididimária do hamster foi notada de forma intensa, sendo confirmada com recente investigação bioquímica de atividade da $\mathrm{FoAl}$, intensa na região da cauda epididimária daquele roedor ${ }^{20}$.

Quanto à atividade da FoAc notouse que foi intensa em praticamente toda a porção apical do epitélio epididimário do gerbilo, exceto no corpo epididimário uma região notoriamente com baixa reatividade histo-enzimática no gerbilo, conforme as observações aqui feitas. A intensa reação apical da FoAc está associada com atividade lisossômica ${ }^{5,8,9,18}$, sendo esta uma observação que implica ocorrência de processos ativos de absorção e endocitose de fluido luminal ${ }^{6,9,18,19}$. No citoplasma basal das células epiteliais epididimárias do gerbilo a reatividade da FoAc foi negativa, sendo este resultado similar ao observado em outros estudos sobre a atividade desta enzima no ducto epididimário de outros mamíferos ${ }^{4}$.
Contudo, a distribuição de reatividade da FoAc nas células do epitélio epididimário, nos diferentes segmentos, mostrou características espécie específicas, como se pode verificar anteriormente ${ }^{4,10,11}$.

Concernente à atividade da ATPase no epitélio epididimário do gerbilo esta foi verificada na porção apical do epitélio tubular em todos as regiões epididimais, exceto no corpo que mostrou atividade entre fraca e negativa. Esta reatividade, intensa no SI e forte na cabeça e cauda epididimários do gerbilo, expressa o papel enzimático da ATPase em termos de transporte ativo de hidrogênio livre do citoplasma apical das células epiteliais para o lúmem epididimário, visando a sua acidificação ${ }^{12}$. A acidificação intraluminal visa a manutenção da quiescência dos espermatozóides no ducto do epidídimo, prevenindo a ativação prematura das enzimas acrossomais ${ }^{12,23}$.

Sabe-se que a ATPase transportadora de prótons $\mathrm{H}^{+}$está localizada principalmente em células claras e delgadas ${ }^{12}$, sendo a quantidade de células claras prevalentes na cauda epididimária do gerbilo ${ }^{15}$, embora sejam notadas também em outros segmentos ${ }^{15}$. Por outro lado, de modo geral a ATPase através da quebra de ATP produz energia para transporte ativo entre a parte apical do epitélio e o lúmem epididimário, ou vice-versa ${ }^{4,6}$, tese com a qual concordamos com base nas observações aqui feitas. Quanto à reatividade forte de ATPase notada na parte basal do epitélio epididimário do gerbilo e na membrana basal da cabeça e cauda epididimais, talvez a ATPase esteja envolvida em transporte ativo entre o epitélio e o tecido conjuntivo subepitelial ${ }^{4}$.

A reatividade da $\mathrm{SDH}$ foi predominantemente fraca no epitélio de revestimento do ducto epididimário do gerbilo em todas as regiões analisadas, sendo este resultado similar ao descrito para o epidídimo do gato ${ }^{13}$. Esta desidrogenase associada às mitocôndrias desempenha papel relevante no ciclo do ácido cítrico sendo a sua atividade caracterizada nas células do epitélio seminífero ${ }^{25,26}$. Assim sendo, esta 
enzima mostrou reatividade intensa no conteúdo luminal do epidídimo de gerbilo predominantemente formado por espermatozóides que possuem grande quantidade de mitocôndrias em nível das peças médias. Sugeriu-se ainda que a atividade da SDH poderia contribuir na marcação das células apicais ricas em mitocôndrias do epitélio epididimal ${ }^{27}$.

\section{Agradecimentos}

Os autores agradecem Sueli Cruz Michelin pelo auxílio técnico. Este trabalho teve o apoio financeiro da FAPESP (Fundação de Amparo à Pesquisa do Estado de São Paulo)

\section{Histochemical localization of some hydrolases in the epididymis of the gerbil}

\section{Abstract}

Key Words:

This study mainly showed that alkaline phosphatase expression had been present in the proximal regions of the epididymidis ductus of the gerbil which comprised the initial segment and proximal caput. The reactivities of acid phosphatase and ATPase were strong in the proximal and distal regions of the epididymidis ductus at the level of the apical cytoplasm and epithelium, except at the corpus level, a very thin isthmus located between the caput and cauda epididymidis, and as a general rule a low enzymatic reactive region of the epididymis of gerbil. SDH revealed also low activities in all the regions and regional structures of the duct, except into the luminal content formed by storaged spermatozoa, prior on the cauda level. The enzymes presented in the epididymis were correlated to some histophysiological roles such as the enzymatic mediation of endocytosis, secretion, absorption and active transport concerning to phosphatases and ATPase and a possible mitochondrial role of SDH could occur at the spermatozoa level in which the middle pieces were formed by a great amount of mitochondria.

\section{Referências}

1 NICANDER, L. On the regional histology and cytochemistry of the ductus epididymis in rabbits. Acta Morphologica Neerlando-Scandinavica, v. 1, p. 99-108, 1957.

2 NICANDER, L. Studies on the regional histology and citochemistry of the ductus epididymis in mammals. Acta Morphologica Neerlando-Scandinavica, v. 1, p. 337-362, 1958.

3 ADAMS, C. S. Localization of alkaline phosphatase and NADH Diaphorase in the principal cells of guinea pig epididymis. Acta Anatomica, v. 116, p. 146-151, 1983.

4 MONIEM, K. A. Comparative histochemical localization of some hydrolytic enzymes in mammalian epididymides. Acta Anatomica, v.108, p.301-309, 1980.

5 BAINTON, D. F. The discovery of lisossomes. The Journal of Cell Biology, v. 91, p. 66-76, 1981.
6 HERMO, L.; OKO, R.; MORALES, C. Secretion and endocytosis in the male reproductive tract: a role in sperm maturation. International Review of Cytology, v. 154, p. 105-19-89, 1994.

7 NICANDER, L. An electron microscopical study of absorbing dells in the posterior caput epididymis of rabbits. Zeitschrift Zellforschung und Mikroskopische Anatomie, v. 66, p. $829-847,1965$.

8 ORSI, A. M.; et al. Morphological investigations of the surface epithelium of ductuli efferentes of black isogenic mice (Mus musculus). Anatomia, Histologia, Embryologia, v. 27, p. 215-218, 1998.

9 HERMO, L.; MORALES, C. Endocytosis in nonciliated cells of the ductuli efferents em the rat. American Journal of Anatomy, v. 171, p. 59-74, 1984.

10 ARIYARATNA, H. B. S.; GUNAWARDANA, V. K.; NAVARATNE, M. A. The epididymis of the prepubertal (Bubalus bubalis): histochemistry of phosphatases. Anatomia, Histologia, Embryologia, v. 25, p.161-165, 1996.

11 HOLT, W. V.; JONES, R. C.; SKINNER, J. D. Studies 
of the deferent ducts from the testis of the African elephant, Loxodonta africana. histochemistry of the epididymis. Journal of Anatomy, v. 130, p. 367-379, 1980.

12 BROWN, D.; SMITH, P. J. S.; BRETON, S. Role of $\mathrm{V}$-ATPase-rich cells in acidification of the male reproductive tract. Journal of Experimental Biology, v. 200, p. 257-262, 1997.

13 VIOTTO, M. J. S., ORSI, A. M., DAL-PAI, V. Localização histoquímica da NADH-diaforase e succinato-desidrogenase no epidídimo do gato (Felis domestica, L.). Ciência e Cultura, v. 38, p. 2025-2027, 1986.

14 FOUQUETT, J. P.; GUHA, S. Histochemical studies on the enzymes of glycogen metabolism in hamster epididymis. Histochemie, v. 17, p. 89-98, 1969.

15 DOMENICONI, R. F.;et al. Características estruturais do ducto epididimário de gerbilo: histologia regional em microscopia óptica. In: CONGRESSO BRASILEIRO DE ANATOMIA, Maceió,20; 2002,Maceió,AL Anais. Maceió, 2002. p. 129.

16 PEARSE, A. G. E. Histochemistry: theoretical and applied. Boston: Little Brown, 1972. p. 180.

17 HOFFMANN, W.E.; KRAMER, J.; MAIN, A.R. Clinical enzimology. In: LOEB W.F.; GUIMBY F.W. (eds). The clinical chemistry of laboratory animals. New Yor: Pergamon Press, 1989. p. 237-278.

18 HERMO, L.; DWORKIN, J.; OKO, R. The role of the epithelial clear cells of the rat epididymis in the disposal of the contents of cytoplasmic droplets detached from spermatozoa. American Journal of Anatomy, v.183, p.107-124, 1988.

19 ROBAIRE, B.; HERMO, L. Efferent ducts, epididymis, and vas deferens structure, functions, and their regulation. In: KNOBIL, E.; NEILL, J. D. The Physiology of Reproduction. 1. ed. New York: Raven Press, 1988. p. 999-1080.

20 BEU, C. C. L.;et al. GALHARDI, C. M. Biochemical analysis of alkaline phosphatase in regions of the epididymis of the golden hamster (Mesocricetus auratus). Theriogenology, sent to publish, 2004.

21 CUMMINS, J. M. Effects of epididymal occlusion on sperm maturation em the hamster. Journal of Experimental Zoology, v.197, p.187-190, 1976.

22 ORGEBIN-CRIST, M. C.; OLSON, G. E. Epididymal sperm maturation. In: COUROT, M. The Male in Farm Animal Reproduction, 1984, p.80-102.

23 CARR, D. W.; USSELMAN, M. C.; ACOTT, T. S. Effects of $\mathrm{pH}$, lactate, and viscoelastic drag on sperm motility: species comparison. Biology of Reproduction, v.33, p.588-595, 1985.

24 HORAN, A. H.; BEDFORD, J. M. Development of the fertilizing ability of spermatozoa in the epididymis of the syrian hamster. Journal of Reproduction and
Fertility, v.30, p.417-423, 1972.

25 LEHMANN, V.; BRANDAU, H. Verteilungmuster von Dehydrogenasen des Glucose-und-FructoseSroffwechsels in Sammenkanalchen des Rattenhodes. Acta Histochemica, v. 35, p. 18-27, 1970.

26 MIRAGLIA, T.et al. Dados sobre a histoenzimologia dos testículos de saguis (Callinthrix jacchus e Callinthrix penicillata). Ciência e Cultura, v. 32, p 1253-1256, 1980.

27 PALACIOS, J.et al. REGADERA. J., NISTAL, M. PANIAGUA, R. Apical mithocondria-rich cells in the human epididymis: an ultrastructural, enzymohistochemical, and immunohistochemical study. Anatomical Record., v. 231, p. 82-88, 1991. 